\title{
Rates and Predictors of Episiotomy in Nigerian Women
}

\author{
Hyacinth E. Onah, ${ }^{l}$ and Chris I. Akani ${ }^{2}$ \\ ${ }^{I}$ Department of Obstetrics and Gynaecology, University of Nigeria Teaching Hospital Enugu, and \\ ${ }^{2}$ Department of Obstetrics and Gynaecology, University of Port Harcourt Teaching Hospital Port \\ Harcourt, Nigeria
}

\begin{abstract}
Background: Despite many years of it being practised, episiotomy has remained controversial operation.

Objectives: To determine (1) the rates of episiotomies in two tertiary care Nigerian obstetric populations; (2) the predictors of a parturient receiving an episiotomy and (3) the frequency, and type, of perineal injuries when an episiotomy is avoided in a given parturient and (4) whether parturients in the centres were taught the technique of antenatal perineal massage.

Methods: A retrospective analysis of consecutive vaginal deliveries by women at two Nigerian tertiary hospitals from $1^{\text {st }}$ May to $30^{\text {th }}$ June 2002.

Results: Out of the 433 vaginal deliveries with complete data, 175 women (40.4\%) had an episiotomy performed during delivery while the remaining $258(59.6 \%)$ did not. Of these 258 women who did not have an episiotomy, 77 $(29.8 \%)$ sustained a first-degree perineal tear, $2(0.8 \%)$ a second-degree perineal tear, $0(0.0 \%)$ a third-degree perineal tear while in $179(69.4 \%)$, the perineum remained intact. The women who had an episiotomy had greater postpartum blood loss than those who did not have an episiotomy (mean recorded blood loss: $328 \pm 345$ versus $235 \pm$ $337 \mathrm{mls}, \mathrm{p}=0.04$ ). The significant predictors of a parturient having an episiotomy were: maternal age less than 30 years compared to those 30 years and older $(\mathrm{OR}=1.6,95 \% \mathrm{CI}=1.3$ to $2.0, \mathrm{p}=0.000)$ and primigravidity compared to other gravidas $(\mathrm{OR}=3.1,95 \% \mathrm{CI}=2.4$ to $3.9, \mathrm{p}=0.000)$.

Conclusions: The episiotomy rate among Nigerian parturients is $40 \%$. Maternal age less than 30 years and primigravidity are significant predictors of episiotomy. Perineal lacerations are associated with less blood loss than episiotomies. Finally, Nigerian parturients should be taught the technique of antenatal perineal massage since this prevents both episiotomies and perineal lacerations.
\end{abstract}

Key words: Episiotomy, rate, predictors, Nigeria

\section{Introduction}

An episiotomy is usually given to prevent perineal injury in a parturient. Despite many years of it being practised, the operation of episiotomy has remained controversial. This is because the operation, if performed without good judgement or repaired without due skill, can be the cause of considerable maternal discomfort and actual morbidity during the puerperium $^{1,2}$. It also contributes to sexual difficulty subsequently. Determining when not to give an episiotomy requires a lot of surgical judgment and common sense. ${ }^{3}$. Yet this may be difficult with the usually large number of health care personnel who attend to parturients in many obstetric units. This study had the following objectives: 1) to determine the rates of episiotomies in two tertiary care Nigerian obstetric populations; 2) to determine the predictors of a parturient receiving an episiotomy 3 ) to determine the frequency, and type, of perineal injuries when an episiotomy was avoided in a given parturient and (4) whether parturients in the centres were taught the technique of antenatal perineal massage.

\section{Materials and Methods}

This was a retrospective analysis of consecutive vaginal deliveries by women of unknown HIV status at the University of Nigeria Teaching Hospital (UNTH), Enugu and the University of Port Harcourt Teaching Hospital (UPTH), Port Harcourt, both in Nigeria from $1^{\text {st }}$ May to $30^{\text {th }}$ June 2002. These deliveries occurred just before the commencement of the Prevention of Mother to Child Transmission (PMTCT) of HIV/AIDS programmes in these two tertiary care Nigerian centres.

Study variables were extracted from the delivery registers of both hospitals and analyzed with descriptive and inferential statistics at the $95 \%$ confidence level.

\section{Results}

Out of the 455 women who had vaginal deliveries during the study period, 433 (230 from UNTH and 203 from UPTH) had complete data and were analyzed. Their mean parity was $2.9 \pm 1.9$ (range: $1-10$ ) and mean age $29.5 \pm 4.9$ (range: $17-43$ ) years. One hundred and seventy-five women $(40.4 \%)$ had an episiotomy performed during delivery while the remaining 258 (59.6\%) did not. The episiotomy rates in the two study institutions did not differ significantly $(38.5 \%$ versus $39.6 \%, p>0.05$ ). Of the 258 women who did not have an episiotomy, $77(29.8 \%)$ sustained a first-degree perineal tear, $2(0.8 \%)$ a second-degree perineal tear, $0(0.0 \%)$ a third-degree perineal tear while in 179 $(69.4 \%)$, the perineum remained intact. On the whole,

Correspondence: H. E. Onah, P O Box 3709 General Post Office Enugu, Nigeria. 400001

E-mail: hyacinon@infoweb.abs.net 
$254(58.7 \%)$ of the parturients either received an episiotomy or sustained a perineal laceration.

The women who had an episiotomy were significantly younger (mean age: $27.8 \pm 4.8$ versus $30.6 \pm 4.7$ years, $p$ $=0.000$ ), were of lower parity (mean parity: $1.8 \pm 1.2$ versus $3.7 \pm 2.0, p=0.000$ ) (Table 1) and had greater

Table 1

The relationship between parity and episiotomy/ perineal tears among $\mathbf{4 3 3}$ parturients in Enugu

\begin{tabular}{cccccc}
\hline & \multicolumn{4}{c}{ Episiotomy } & \multicolumn{2}{c}{ Perineal tear } \\
Parity & Total & No & $\%$ & No & $\%$ \\
\hline 1 & 130 & 99 & 76.2 & 5 & 3.8 \\
2 & 99 & 38 & 38.3 & 25 & 25.3 \\
3 & 68 & 22 & 32.3 & 14 & 20.6 \\
4 & 47 & 9 & 19.1 & 16 & 34.0 \\
5 & 39 & 4 & 10.3 & 12 & 30.8 \\
6 & 23 & 1 & 4.3 & 5 & 21.7 \\
7 & 16 & 1 & 6.3 & 1 & 6.3 \\
8 & 7 & 0 & 0.0 & 1 & 14.3 \\
$>8$ & 4 & 1 & 25.0 & 0 & 0.0 \\
\hline Total & 433 & 175 & 40.4 & 79 & 18.2 \\
\hline
\end{tabular}

postpartum blood loss (mean recorded blood loss: 328 \pm 345 versus $235 \pm 337 \mathrm{mls}, \mathrm{p}=0.04)$ than those who did not have an episiotomy. On univariate logistic regression, the following variables were significant predictors of the likelihood of having an episiotomy: maternal age less than 30 years compared to those 30 years and older $(\mathrm{OR}=1.6,95 \% \mathrm{CI}=1.3$ to $2.0, \mathrm{p}=$ 0.000 ) and primigravidity compared to other gravidities $(\mathrm{OR}=3.1,95 \% \mathrm{CI}=2.4$ to $3.9, \mathrm{p}=0.000)$. These two variables remained significant on multivariate logistic regression $(p<0.05)$. Gestational age at delivery, birth weight, instrumental vis-à-vis spontaneous vaginal delivery and midwife versus doctor as the accoucher were not significant predictors of the likelihood of a parturient having an episiotomy. There was no record of perineal massage being taught to the women during the antenatal period in both hospitals.

\section{Discussion}

This study has shown that without the knowledge of the HIV status of a parturient, approximately two-fifths of Nigerian parturients, especially young primigravidas, have an episiotomy performed on them during parturition. This rate is higher than the $10 \%$ recommended by the World Health Organisation ${ }^{4}$ and $10-30 \%$ found in a recent survey of maternity units in the United Kingdoms. Another one-third of women in whom the caregiver did not feel that an episiotomy was necessary sustained various degrees of perineal injury. On the whole therefore, approximately two-thirds of Nigerian parturients either receive an episiotomy or sustain a perineal laceration.

Given the significantly lower parity of those who received an episiotomy than those who did not, it is highly probable that more than one-third of the parturients might have sustained perineal injury if an episiotomy had been avoided in all of them. However, perineal lacerations, which might have occurred if episiotomies had been avoided, were associated with less blood loss than episiotomies. Several studies have shown that perineal massage in the third trimester-8 (but not during labour') can significantly reduce the incidence of both episiotomies and perineal lacerations during vaginal delivery. Despite this, the pregnant women in both institutions of study were not taught the technique of antenatal perineal massage. There is no doubt that if this had been done, it would have minimized both episiotomies and perineal lacerations in the parturients. Antenatal perineal massage is recommended.

We conclude that the episiotomy rate in Nigerian parturients of unknown HIV status is $40 \%$, that maternal age less than 30 years and primigravidity are significant predictors of episiotomy and that perineal lacerations, which may occur when episiotomies are avoided, are associated with less blood loss than episiotomies. Finally, pregnant women (especially primigravidas and those aged less than 30 years) should be taught the technique of antenatal perineal massage since this prevents both episiotomies and perineal lacerations.

\section{References}

1. Myerscough PR. Munro Kerr's Operative Obstetrics. $10^{\text {th }}$ Ed. London: Balliere Tindall, 1982:453-457.

2. Cunningham FG, MacDonald PC, Gant NF, Leveno KJ, Gilstrap III LC, Hankins GDV, Clark SL. Williams Obstetrics. 20 $0^{\text {th }}$ ed. Connecticut: Appleton \& Lange 1997: 342-343.

3. Argentine Episiotomy Trial Collaborative Group. Routine versus selective episiotomy: a randomised controlled trial. Lancet 1993; 342:1517-1518.

4. Quoted in Johanson R. Obstetric procedures. In: Edmonds DK(Ed). Dewhurst's Textbook of Obstetrics and Gynaecology for Postgraduates. $6^{\text {th }}$ Ed. Oxford: Blackwell Science: 308-312.

5. Audit Commission.First Class Delivery: improving maternity services in England and Wales. 1(Abstract). Abingdon: Audit Commission Publications: 1997.

6. Keenan P. Benefits of massage therapy and use of a doula during labor and childbirth. Altern Ther Health Med 2000;6:66-74.

7. Eason E, Labrecque M, Wells G, Feldman P. Preventing perineal trauma during childbirth: a systematic review; Obstet Gynecol; 2000; 95:464-71.

8. Labrecque M, Eason E, Marcoux S, Lemieux F, Pinault $J J$, Feldman P, Laperriere L. Randomized controlled trial of prevention of perineal trauma by perineal massage during pregnancy. Am J Obstet Gynecol 1999; 180:593600.

9. Stamp G, Kruzins G, Crowther C. Perineal massage in labour and prevention of perineal trauma: randomized controlled trial. BMJ 2001;322(7297): 12771280. 